\title{
Trabajo, ideologías sobre el trabajo y culturas del trabajo
}

ISIDORO MORENO NAVARRO*

\section{Introducción}

El título del reciente y conocido libro de Jeremy Rufkin resume perfectamente las ideas hoy dominantes sobre la situación actual y el futuro del trabajo, al menos en las sociedades del que, hasta hace unos años, venía denominándose "Primer Mundo", es decir, en los paises centrales del sistema capitalista (incluyendo tanto los que son realmente centro como los que constituyen la periferia interna del mismo, como es el caso del Estado Español, del que Andalucía es, a su vez, periferia).

No es sólamente en libros realizados sobre la base de análisis más o menos adecuadös, o como ensayos con aspiración de best-sellers, donde se argumenta en esta dirección, sino también en multitud de artículos y colaboraciones en diarios y revistas de difusión muy amplia. "El empleo ha muerto. No hay empleo ni, quizá, volverá a haberlo más. Al menos, según el concepto tradicional: con horario, ascensos y sueldo fijo. El trabajo que viene es flexible, por definición. Y el cambio no afecta sólo a los parados; si usted tiene trabajo, también puede perderlo. Ha llegado la hora de que cada uno invente su propio futuro" , se afirmaba en un amplio documento-reportaje periodístico publicado hace no mucho en el dominical del más influyente y reputado diario madrileño . Y los ejemplos podrían multiplicarse, no sólo en prensa sino también en tertulias de radio y TV y en los discursos de casi todos los políticos e incluso, aunque sottovoce, de no pocos sindicalistas.

Es bien significativo que, sin embargo, apenas exista debate sobre el análisis de la situación actual, sobre sus causas y efectos, aunque sí lo haya en cuanto a las medidas para eliminar, en lo posible, las aristas más agudas de estos últimos. Desde los más ortodoxos neo(ultra)liberales hasta los más conspicuos representantes de la izquierda socialdemócrata - casi toda ella reconvertida en social-liberal--, todos aceptarían suscribir, casi con unanimidad, las anteriores frases. La situación es considerada no sólo irreversible sino que es tratada como inevitable. Y, sin embargo, convendría hacer un esfuerzo para no dejarnos

*. Catedrático de Antropología de la Univrsidad de Sevilla. 
llevar por esta fuerte corriente mayoritaria y dominante, e intentar separar las constataciones de las interpretaciones, reflexionando sobre estas por más que se nos presenten también como si fueran evidencias contrastadas.

\section{EI mito de la mundialización de la economía}

Muy pocos se atreven hoy a plantearse, y aún menos a discutir, si realmente estamos inmersos en un proceso de mundialización total de la economía. Esto parece algo obvio, y, sin embargo, no lo es. Se parte de ello como de un axioma, cuando, en realidad, se trata de un mito que importa desvelar y deconstruir. Lo que está mundializado, o al menos en avanzado proceso de estarlo, no es el conjunto de la economía sino el mercado, pero incluso en éste no todos los factores lo están, ni lo estarán en el futuro. Sí es cierto que está ya prácticamente mundializado el mercado de capitales, el mercado de tecnología y el mercado de las comunicaciones (incluido el de la llamada información ). También lo está, en su mayor parte, con tendencia a estarlo totalmente, el mercado de productos tanto materiales como de servicios e intelectuales. Pero en ningún modo está mundializado, ni se halla en esa dinámica, el mercado de fuerza de trabajo, $o$, si se quiere, de recursos humanos (el cambio de palabras no supone, o al menos no debería suponer, una modificación de la realidad a la que hacen referencia ni una distinta visión de ésta, aunque ello sí ocurra generalmente, debido a la carga simbólica que las propias palabras poseen).

No todo el mercado se halla, pues, mundializado ni en vías de mundialización, y aún menos toda la economía. No todas las mercancías están sujetas al mismo proceso de liberalización y derrumbe de fronteras. El capital sí es, cada vez más, trasnacional y se mueve cada día con menos trabas. Y lo mismo es cierto, como ya hemos señalado, para la tecnología y la mayor parte de los productos, sean o no manufacturados, aunque también sabemos que se están consolidando áreas, con sus respectivas periferias, donde el libre mercado es interior y actúan diversos proteccionismos respecto al exterior. El flujo de trabajadores, sin embargo, salvo dentro de estas áreas —USA, la Unión Europea y Japón principalmente-, no sólo no se facilita sino que se restringe y dificulta con fuertes barreras legales y policiales respecto a la situación existente hace unos años. Los ciudadanos de los "terceros países", no importa qué nivel de cualificación tengan y menos qué necesidades económicas y/o políticas, no gozan de la mundialización que se afirma posee el mercado, todo el mercado, y las mercancías, todas las mercancias. A la libre circulación de capitales no se corresponde una igualmente libre circulación de trabajadores. Los capitales, la tecnología y los productos del centro sí se extienden a todas las periferias, pero las personas de la periferia no pueden desplazarse al centro. Una vez más, no hay equiparación ni relación igualitaria entre capital y trabajo. Ni tendríamos por qué esperarla a menos de ser ingenuos, podría añadirse. Y es cierto, pero entonces no hablemos de mundialización del mercado y menos de globalización de la economía como si ello fuera una verdad evidente. 
Cuando magrebíes, subsaharianos o albaneses pretenden entrar en el territorio de la UE, se utiliza la palabra invasión, aunque se añada que pacífica. La entrada en el centro está hoy cerrada legalmente, salvo para muy pequeños cupos, cuantitativamente poco relevantes. Por eso, a los estigmatizados como ilegales se les devuelve, a veces no demasiado pacíficamente, a sus lugares de origen. Pero cuando los grandes bancos y las grandes corporaciones industriales se instalan en el antes llamado Tercer Mundo, y llevan a este su tecnología industrial y financiera, destruyendo el débil tejido industrial-artesanal previamente existente y desestructurando sus redes comerciales tradicionales, no se habla de invasión sino de llegada del progreso, incluso de cooperación al desarrollo. Y ello aunque sea evidente que este supuesto progreso se realiza aprovechando, y contribuyendo activamente a perpetuar, situaciones políticas y sociales que son con frecuencia despóticas cuando no sanguinarias, pero que son legitimadas cínicamente por Occidente en base a la celebración de rituales electorales. Son precisamente esas situaciones de negación de Derechos Humanos las que permiten que las grandes corporaciones de capital trasnacional puedan libremente sobreexplotar, sin distinción de sexo ni edades, a una abundante mano de obra que produce a muy bajos costes y en condiciones que recuerdan, o sobrepasan, en dureza y crueldad las del capitalismo salvaje de mediados del XIX en Europa. Es sobre esta combinación de capitalismo oligopólico, nuevas tecnologías y abundante fuerza de trabajo en condiciones miserables y carente de derechos, sobre la que está teniendo lugar el espectacular crecimiento económico -que no desarrollo- de una serie de países que pueden ser ejemplificados en los conocidos como "cinco dragones" del sureste asiático. Un crecimiento que está produciendo grandes aumentos en las cifras del PIB pero que no repercute en mejora de los niveles de vida ni las condiciones de trabajo de la población sino que acentúa la proletarización y miseria económica y moral de esta. Los espectaculares beneficios lo son del capital trasnacional, que no es ninguna abstracción sino que encarna en personas físicas y jurídicas de los países centrales a las que se añaden unos pocos individuos o familias de las viejas, o nuevas, oligarquías locales.

\section{El "fin del trabajo" en los países centrales}

¿Cuál ha sido la repercusión de esta forma concreta de mundialización del mercado de capitales y tecnología sobre los países del centro del sistema? Al introducirse en estos un gran número de mercancías de consumo producidas en el Tercer Mundo a muy bajo costo, con tecnología y capitales procedentes del centro - no se olvide esto, so pena de malentender completamente la situación-, se hace muy difícil la competencia con ellas de los productos equivalentes fabricados en los países tradicionalmente industrializados, sobre todo en relación a garantizar al capital una misma alta tasa de beneficios. Es ésta la causa principal del desmantelamiento de sectores enteros de la producción, que pasan a otras áreas geográficas del planeta, y de las continuas reestructuraciones de los procesos 
productivos, con objeto de abaratar costos y sobrerrentabilizar el capital financiero. Estas reestructuraciones consisten, sobre todo, en la aplicación de innovaciones tecnológicas cada vez con un ciclo más corto, basadas en lo que se ha denominado el complejo cibernético-informático, y en el recorte de los costos salariales mediante la destrucción de puestos de trabajo y la "informalización" de un número cada vez mayor de eslabones de los procesos productivos. El paro, la precarización y el trabajo negro o "sumergido" se han convertido, así, en factores estructurales de las economías de los países centrales, mientras la tasa de beneficios de las grandes corporaciones y sociedades se multiplica a mayor ritmo que en ninguna otra época. Hasta el punto que, ya hoy, como señala Alfonso Ortí , la sobreacumulación de activos financieros ha hecho que estos se reconduzcan hacia actividades cada vez más especulativas y menos ligadas a la producción real.

No es una paradoja, sino algo completamente coherente, que en los últimos años, una vez superado el bienio 92-93, coincidan, tanto a nivel mundial como en el marco de cada Estado y área económica, un espectacular y continuo crecimiento de beneficios de las grandes empresas y entidades bancarias y un también claro ascenso, $o$ al menos no reducción, de las cifras de paro. Un hecho general que está especialmente presente en el Estado Español y en Andalucía.

Los efectos de esta situación sobre los puestos de trabajo son evidentes: las empresas, sobre todo las que están en manos del capital trasnacional, junto a reconversiones tecnológicas permanentes, muy intensivas en capital, y a una política de deslocalización productiva —que ha dado lugar a la hoy llamada industria difusa, con elevado nivel de "informalización"-, han emprendido una estrategia de reducción y "flexibilización" de la fuerza de trabajo con despidos masivos sucesivos en también casi permanentes reconversiones: las menos sofisticadas acudiendo al cierre de factorías o al fomento de las jubilaciones anticipadas y las bajas "voluntarias" de buena parte de sus plantillas, y las más "modernas" organizando el downsizing , como púdica o, mejor, cínicamente las llaman, incluso entre nosotros, los tecnócratas especializados en "Recursos Humanos", en este caso para disminuirlos en cada empresa "con los menores costes" (se entiende que para la productividad de las empresas).

Muchos afirman que, a nivel mundial, estamos entrando en la "era postindustrial" , y ello podría ser cierto, al menos relativamente, referido a los países del centro del sistema, que es donde se están desmantelando muchos distritos y comarcas antes altamente industrializados, pero no para los aludidos países del Tercer Mundo, que precisamente ahora están siendo introducidos en la era de la industrialización a través de la puesta en marcha de procesos productivos que combinan una muy intensiva inversión de capital en tecnología y una sobreexplotación, que parecía ya olvidada, de una abundantísima mano de obra en general muy descualificada. 
Es esta "nueva" era la que es caracterizada como la del fin del trabajo: el fin del empleo estable y cualificado, del puesto de trabajo fijo para toda la vida, y en muchos casos en una misma empresa, con horarios fijos, sueldo estable y posibilidad de ascensos. Frente a ello, que se afirma periclitado, se propugna, como el medio idóneo para conseguir una mayor productividad y competitividad empresariales - los dos valores absolutos y axiomáticos, y por ello sacralizados, del presente-, la flexibilización del mercado de trabajo y la polivalencia de los trabajadores. Ello se traduce, en primer lugar, en la necesaria disponibilidad de estos para moverse sucesivamente desde una situación de empleo a una de paro y desde ésta a otro puesto de trabajo, también temporal, distinto al precedente. Es lo que algunos llaman "pasar del empleo de por vida a la empleabilidad de por vida". Para facilitar lo cual se procede a la desregulación del mercado de trabajo, es decir, a la anulación de gran parte de las conquistas legales obtenidas por los trabajadores como consecuencia de más de cien años de lucha. Anulación que se está realizando en casi todos los países con la colaboración activa, o al menos la anuencia, de los sindicatos otrora de clase y hoy convertidos, en la gran mayoría de los casos, en aparatos burocráticos de Estado. Se afirma ahora, de manera que no podría calificarse sino de cínica, que de lo que se trata es de conseguir la igualdad entre ambas partes, empresarios y trabajadores, permitiendo a unos y a otros establecer y romper sus relaciones contractuales cuando les interese, sin más complicaciones. Lo que, sin duda, supone eliminar los obstáculos para el libre comportamiento de los patronos pero no es otra cosa que una pura ilusión de libertad para los asalariados, ya que las relaciones entre ambos colectivos jamás pueden ser igualitarias porque son estructuralmente asimétricas.

La flexibilización no sólo se predica para el mercado de trabajo sino también para la organización del trabajo dentro de las empresas, propugnándose la aceptación por parte de los trabajadores de la movilidad funcional y geográfica siempre que convenga a los intereses de la producción. A ello se une la imposición, abierta o subrepticia, de contratos de trabajo temporales y/o a tiempo parcial, y el establecimiento de horarios y salarios variables e irregulares. Además, existe una fuerte tendencia a la supresión de numerosos niveles de gestión y a la subcontratación de empresas, a menudo no legalizadas, para la realización de aspectos o partes importantes de la gestión o del propio proceso productivo. Crecientemente, ello se realiza mediante "relaciones flexibles", es decir, sin contrato formalizado, o formalizado sólo por tareas, con autoempleados, como ocurre a través del denominado "teletrabajo", el cual, a pesar de su aparente modernidad, no es otra cosa que una versión actualizada del tradicional trabajo a domicilio : una forma de subempleo o "aparcería moderna" que no lleva en modo alguno a la situación de autónomo sino a una aguda dependencia. Esta falsa autonomía, que es en realidad una situación de total desprotección y carencia de derechos ante las empresas, prolifera hoy en los sectores industrial y de servicios, llevando a quienes caen en ella a la imposibilidad de toda reivindicación laboral y de toda posibilidad de asumir valores sociales que se generan en la experiencia compartida de la subalter- 
nidad y en la sociabilidad entre iguales, es decir, a través del trabajo junto a otros en unos mismos lugares de trabajo.

\section{La reconversión ideológica: los cambios en la ideología dominante sobre el trabajo}

De acuerdo con la nueva situación, que ha sido definida como de capitalismo financiero especulativo y neotecnológico, y sobre todo para su aceptación con las menores resistencias posibles, se ha hecho necesaria una reconversión no menos importante que la tecnológica y la realizada en la organización del trabajo: la reconversión ideológica. Suele afirmarse, y ello es cierto, que el neoliberalismo como doctrina es hoy la ideología dominante. Pero conviene no sólo señalar sus principales elementos componentes y sus más evidentes efectos - que es lo que generalmente se hace-, sino dibujar también su marco de referencia implícito a partir del cual cobra todo su sentido. Este marco es el proceso de sacralización del Mercado.

Como ya he desarrollado en otros lugares, la esfera de lo sagrado, que es aquella propia de los absolutos sociales como señalara Durkheim, estuvo durante milenios ocupada, al unísono y en estrecha fusión, por la Religión y el Estado. Concretada en cada formación social y cada época en creencias, valores, rituales, prácticas sociales y gestores específicos, esta fusión sacralizada de lo religioso y lo político -que en la Edad Media europea, y en España hasta bien entrado el siglo XIX, se llamó la alianza entre el Trono y el Altar-, garantizó el orden económico-social y su reproducción aún por encima de las discontinuidades en los modos de producción. Las doctrinas reveladas por el Dios de turno, o elaboradas en su nombre por sus vicarios y altos funcionarios, constituían la explicación extrasocietaria, "sobrenatural", del mundo y del orden social de cada sociedad, legitimando éste, simbólicamente representado por el soberano, que en ocasiones llegó a encarnar ambos absolutos, el político y el religioso - y que incluso cuando no fue así era considerado monarca "por la gracia de Dios"-, con la obligación de velar por su perpetuación. Las relaciones sociales desigualitarias de sexo, étnicas y entre clases sociales eran atribuidas al orden del mundo y de las cosas, establecido de una vez y para siempre por la deidad, y no a mecanismos y estructuras producidos por la sociedad misma. En esta larga época, el trabajo era la actividad obligada de los colectivos identitarios subalternos: mujeres (sobre todo en el trabajo doméstico y en labores de muy bajo prestigio social), pueblos dominados (que tienen que trabajar para pagar los impuestos o tributos al dominador) y clases oprimidas (según las épocas, esclavos, siervos o trabajadores "libres"). El trabajo, por tanto, entendido como trabajo manual, era considerado un tormento o tortura - recuerdese que el término latino tripaliare significa justamente esto-, y un resultado de la comisión de actos o pecados contrarios a la divinidad: el pasaje del Génesis es bien explícito al respecto y mitos equiva- 
lentes existen en muchas otras culturas. Sólo quienes participaban de algún modo del sacro religioso y/o estatal podían escapar a esa tortura del trabajo: para el caso del sacro religioso, sacerdotes, curadores, astrólogos y componentes de colectivos dedicados a reverenciarlo -órdenes religiosas, vestales, etc.-. Al igual que gobernantes, guerreros, escribas y juristas por su conexión con el sacro Estado. Unos y otros podían dedicarse a la dirección de los asuntos públicos y a propiciar la protección sobrenatural de la sociedad porque esta se basaba en el trabajo que realizaban para ellos la gran mayoría de la población, el cual les llegaba en forma de tributos, impuestos o diezmos (lo que se ha denominado apropiación del excedente, aunque el propio concepto de "excedente" sea muy discutible). La ideología del orden social reglado por la divinidad y la idea de "servicio" a la comunidad, incluso de "sacrificio" por la comunidad, que sería la función de las clases dominantes eran los ejes del consentimiento social a la dominación, percibida no como tal sino como orden sobrenatural y como garantía de la protección.

Una novedad muy importante supuso la doctrina calvinista y, en general, de las iglesias reformadas respecto a la consideración del trabajo: ahora éste no es sólo un recuerdo del estigma del pecado, ni un posible aunque heroico medio de santificación personal si se combinaba con la oración, como ya había sido contemplado por algunas minorías en el Medioevo, sino que el éxito en él suponía ya un signo de predestinación, de haber sido favorecido por el Absoluto. Como señalara lúcidamente Max Weber, esta inflexión ideológica estuvo estrechamente relacionada con el gran impulso del capitalismo. Pero, además, constituyó la base para una ética puritana del trabajo: el trabajo no es, desde entonces, ya propiamente un castigo sobrenatural sino un imperativo ético dictado desde la divinidad.

Tímidamente desde el Renacimiento y ya de forma acentuada desde la Ilustración, en Occidente el sacro religioso fue siendo desplazado de la centralidad de lo sagrado por la Razón sacralizada, es decir, por la lógica racionalista europea, manteniendose como sacro el Estado, crecientemente legitimado por la racionalidad en lugar de, o además de, por la religión. "Hacer entrar en razón", o lo que es lo mismo "civilizar", se convierte en la justificación ideológica legitimadora de la dominación europea sobre los otros pueblos del mundo, sustituyendo en su misma función a los discursos anteriores de la "evangelización" y la lucha contra los "infieles". Y es, también, por ser definidos los hombres como dotados de mayor racionalidad que las mujeres, y ser caracterizadas éstas como más intuitivas e inestables emocionalmente, por lo que lo masculino se fundamenta ahora como superior a lo femenino. La ideología legitimadora de las desigualdades no descansa ya en lo sobrenatural, sino en la naturalización de las relaciones y valores sociales: las razas inferiores y el sexo inferior están destinados por naturaleza a trabajar: de ahí la permanencia de la esclavitud o, en todo caso, de la exclusión no sólo económica sino social y política de todos los pueblos no occidentales y de todas las mujeres. Sólo los dominantes: europeos (y luego también norteamericanos y otros grupos de raíz europea en los diversos continentes) y va- 
rones, están llamados a las actividades significativamente no calificadas como "trabajo": gobernación, sacerdocio, profesiones liberales, comercio a gran escala, siempre que pertenezcan a las élites dominantes. Sólo los europeos varones que no forman parte de dichas élite pueden hallar en otros trabajos, más modestos —estos sí considerados como "trabajos"-, el camino para vivir cristianamente las penalidades terrenas cumpliendo así su función en la vida. Para unos y otros, pero sólo para los europeos varones, es funcional la ética puritana sobre el trabajo.

En el siglo XIX la concepción marxiana plantea por primera vez la distinción entre el concepto de trabajo y el de "trabajo alienado". La consideración del trabajo se realiza, así, en base a la estructura de cada sociedad o, más bien, a la del modo de producción que es dominante en ella, y no a esferas extrasocietarias, sean sobrenaturales o naturales. Bajo relaciones sociales de producción asimétricas y de dominación, el trabajo pierde su valor fundamental de constituir la articulación entre la actividad material y la actividad intelectual; valor que sólo será posible recuperar en el marco de una sociedad sin clases. Conviene no minimizar las implicaciones de este planteamiento, a pesar de las evidentes insuficiencias del análisis marxista respecto a la explicación de las relaciones sociales de sexo y de las relaciones interétnicas y nacionalitarias, porque en él, dado el carácter de clase que explícitamente conlleva el trabajo, éste, a pesar de ser en las sociedades capitalistas trabajo alienado, se considera como el nexo principal entre quienes están llamados a construir revolucionariamente la sociedad socialista, que sería precisamente aquella sociedad en la que "a cada quién se dará según su trabajo". Fue muy importante el papel tanto del marxisr o como de las diversas corrientes del denominado socialismo utópico en la dignificación ceel trabajo a los ojos de quienes tenían que sufrirlo, sin que ello supusiera legitimar las formas y condiciones en que este se desarrollaba. En esto existen tanto semejanzas como diferencias respecto a la ética puritana del trabajo que no podemos ahora profundizar.

En el ámbito católico, la no introducción de la ética calvinista sobre el trabajo llevó al mantenimiento de la consideración como innoble del trabajo - la literatura del Siglo de Oro español refleja perfectamente las dificultades de reproducción de la ética tradicional- , aunque aquella va ejerciendo una creciente influencia, que se acentúa sobre todo a través de las ideas enciclopedistas e ilustradas del siglo XVII. Y en su combate contra las ideas liberales y socialistas, ya en el siglo XIX, la Iglesia comienza a preocuparse del "mundo del trabajo", exaltando en su discurso la importancia del trabajo como deber cristiano. Como no pocos autores han señalado, las encíclicas pontificias de las últimas décadas siguen en esta misma línea, siglos antes condenada como calvinista, de considerar el trabajo como medio ordinario de santificación personal, siendo organizaciones como el Opus Dei la versión católica más acentuada de la ética protestante sobre el trabajo. 
En nuestros días, sin embargo, la centralidad del ámbito de lo sagrado ha sido ocupada por el Mercado. Este es hoy el absoluto, el sacro central, por encima del sacro divino y del sacro estatal, que giran hoy en su órbita, y como desarrollo de la sacra Razón. Cuanto no se integra en el Mercado, es decir cuanto no funciona como mercancia, con valor de cambio, está devaluado socialmente o no se percibe siquiera su existencia: así ocurre con el trabajo de las "amas de casa" - que "no trabajan, sino que hacen sus labores" -, o con el trabajo que realizamos para nosotros mismos, aún si posee un gran valor de uso. Y desde esa clave se contempla la situación de los jubilados, de los parados de larga duración y de los jóvenes sin empleo, que son, por ello, socialmente marginales al quedar excluidos del mercado de trabajo.

A pesar de esto, los cambios estructurales a los que al principio nos referíamos, que caracterizan la nueva fase en el desarrollo del capitalismo, están obligando a una reconversión ideológica importante, que es necesaria para legitimar el modelo actual de mundialización del mercado de capitales, tecnología y productos pero no de la fuerza de trabajo. Y que es también precisa, en los países centrales del sistema, para producir el consentimiento de la nueva situación y evitar que los sectores más perjudicados por esta, en especial la clase obrera industrial tradicional y los estratos de trabajadores medios en las diversas actividades, no desemboquen en protestas sociales que pudieran obstaculizar la garantía buscada de una tasa adecuada de beneficios para el capital trasnacional.

Dicha reconversión ha modelado ya una ideología sobre el trabajo que es parte muy importante de la doctrina neo(ultra)liberal, la cual, para extenderse y ser interiorizada por los sujetos sociales, y en especial por los trabajadores, necesita cuartear y debilitar dos constructos que son, a su vez, resultado de todo el desarrollo del capitalismo hasta tiempos muy recientes, con sus contradicciones y luchas. El primero de ellos refiere al corpus legal de derechos reconocidos respecto al trabajo y de obligaciones del Estado respecto a los trabajadores. El segundo, está constituido por las culturas del trabajo que los diversos colectivos de trabajadores han modelado procesualmente como resultado de sus experiencias en procesos de trabajo específicos bajo concretas relaciones de producción.

\section{EI recorte del "estado del bienestar" y la formación de sociedades tripartitas}

En la primera vertiente, se está demontando lo que se dio en llamar "pacto keynesiano", a través del cual la confrontación capital/trabajo derivó en la relación tripartita capital/Estado/sindicatos y en el denominado "Estado del Bienestar", que venía a garantizar la paz social mediante la definición como derechos de las prestaciones estatales por desempleo, las pensiones por jubilación, viudedad o enfermedad, la asistencia gratuita sanitaria, educativa, etc. y los precios políticos para transportes, viviendas y otras necesidades. 
Como es sabido, la dinámica de la actual nueva fase del capitalismo (financiero, especulativo, neotecnólogico y "mundializado") tiende necesariamente a desmontar, o al menos a recortar, este edificio del Welfare State - que en el Estado Español no llegó nunca a estar completamente construido, al menos en comparación con otros países europeos-, como forma de reducir los "gastos extralaborales". A facilitar este objetivo se dirige hoy la ideología del "Estado mínimo" y las ofensivas ideológicas - y presupuestarias- contra todo lo público: tanto en la esfera de la producción, mediante la privatización de las empresas públicas, como en los campos de la educación, la sanidad, la comunicación, los transportes, la vivienda o las pensiones. Las empresas privadas son contempladas, por definición axiomática, como automáticamente más eficaces, productivas y competitivas que las empresas públicas. Lo cual, cuando en concreto es así, tiene mucho más que ver con la burocratización, corruptelas y falta de control generalmente presentes en estas - pero que serían potencialmente eliminables si hubiera voluntad política para ello-, que con su carácter público. Y tiene como objetivo incorporar al mercado "libre" actividades y servicios que son puestos en manos del capital trasnacional como nuevos y muy importantes ámbitos de producción de beneficios, aunque a ellos no sea posible el acceso de sectores cuantitativamente muy importantes de la población si no están total o parcialmente a cargo del Estado. Si este rehusa a su función redistribuidora se produce la exclusión de esos servicios, con la consiguiente marginación, de cada vez más amplios sectores de la población.

Es este proceso en avance el que es definido generalmente como "dualización social", aunque realmente deberíamos considerar que, más que dualismo social, lo que se está modelando, tanto a nivel mundial como en el interior de los estados y formaciones sociales es un modelo tripartito en cuya construcción es determinante la situación de los individuos respecto al mercado de trabajo y a los servicios estatales. Sobre todo, las sociedades centrales y sus periferias interiores están compuestas, ya hoy, por un sector cada vez más amplio de excluidos y marginados ; por otro en aún más rápida expansión de precarios ; y por un tercero al que podríamos llamar de integrados, muy heterogéneo, que es aquel donde persisten formas de organización del trabajo, representaciones ideáticas, ideologías y conflictos que perviven de la fase anterior del capitalismo aunque se hallen en debilitamiento creciente. A este tercer y heterogéneo bloque pertenecen los trabajadores, de cualquier tipo que sean, con contrato fijo, posibilidades de negociación y presión colectiva, y acceso a los servicios del Estado. Es en este sector en el que se desenvuelven las organizaciones sindicales más importantes, que, como aquellos, exhiben un creciente gremialismo corporativista y una ideología cada vez más conservadora, por más que lo hagan disfrazandola de la habitual retórica obrerista. Ello se debe, sobre todo, al miedo de los trabajadores integrados a perder una situación que de ser considerada como un derecho ha pasado a ser calificada desde la ideología neo(ultra)liberal dominante, e incluso ha sido interiorizada por muchos de ellos, como un privilegio . Es esto principalmente lo que explica esta no re- 
conocida pero evidente transformación conservadora de la "clase obrera tradicional" y de los "sindicatos de clase".

La quiebra prácticamente total de la solidaridad entre los trabajadores pertenecientes hoy a los tres distintos bloques y la concentración del interés sindical sólamente en uno de ellos se debe a razones tanto objetivas como ideológicas y está facilitando el avance de la ideología del Estado mínimo. Un buen ejemplo concreto del enfrentamiento latente entre los tres sectores de trabajadores y del desconcierto de las organizaciones tradicionales de la "izquierda", tanto sindical como política, es el actual debate internacional sobre el llamado "reparto del trabajo" que se está promoviendo precisamente desde ellas o por iniciativa de los que hace años hubieran sido llamados sus "intelectuales orgánicos". Dada la actual fortaleza del capital y el casi nulo potencial de verdadera movilización de una fuerza de trabajo más fraccionada objetiva e ideológicamente que nunca, la propuesta de "trabajar menos para que trabajen más" o no pasa de ser pura palabrería demagógica, destinada a justificar la inacción, el conformismo y el colaboracionismo sindical y a tratar de disimular la conversión de los social-demócratas en social-liberales, o es un simple deseo utópico carente de toda viabilidad práctica, o equivale a proponer descaradamente a los trabajadores con salario fijo que repartan una parte de este con los desempleados rehusando a una parte de su tiempo de trabajo. Es bien significativo de la interiorización de la nueva ideología dominante sobre el trabajo por las burocracias sindicales el que en momentos como el actual, en que en Andalucía y España se nos informa que la gran mayoría de los Bancos y Cajas han conseguido en el año 1996 incrementar en un $20 \%$ y más sus beneficios, e igualmente una serie de grandes empresas, no se haya oído voz alguna planteando la procedencia de un cierto reparto de beneficios $\multimap$, lo que sería una vía para ello: el que haya de invertirse obligatoriamente una parte de éstos en la creación de nuevos puestos de trabajo-.

\section{La nueva ideología dominante sobre el trabajo y las culturas del trabajo}

\subsection{Culturas del trabajo y matriz estructural.}

La segunda vertiente que hemos señalado como más importante respecto a los efectos de la nueva ideología neo(ultra)liberal dominante sobre el trabajo - y en la que nos centraremos a partir de aquí- es la de las culturas del trabajo. Desde hace unos años, tanto personalmente como colectivamente en GEISA (Grupo para el Estudio de las Identidades Socioculturales en Andalucía, de la Universidad de Sevilla), venimos utilizando un concepto de culturas del trabajo que intenta superar las limitaciones y unidimensionalidades anteriores del concepto y que inserta a éste en un nuevo marco teórico-metodológico: el de la matriz estructural identitaria . 
Como señalaba hace unos años, el concepto de cultura del trabajo (en singular) venía siendo utilizado por un sector de la sociología italiana y por otro de la etnología francesa. Para los primeros, como exponía Paolo Zurla , la cuestión central era la significación del trabajo, el lugar que este ocupa en la vida de los individuos y su influencia en la vida social. Por cultura del trabajo entienden el conjunto de las representaciones e ideologías existentes sobre el trabajo. En palabras de P. Ceri: "las culturas del trabajo resultan estar formadas por modelos cognitivos, morales y motivacionales con los que los hombres definen, valoran y orientan el trabajo -el suyo y el de los demás-, los resultados obtenidos y sus compensaciones, su situación social y su contenido profesional" . El énfasis, por lo tanto, es puesto en el ámbito ideático, en las concepciones sobre el trabajo.

Los etnólogos franceses, al contrario, partiendo de la tradición de la Tecnología Cultural, centraban sobre todo su atención sobre la cultura técnica : los conocimientos y saberes de los trabajadores en una actividad concreta, la división técnica y social del trabajo y las formas de organización de éste, la construcción de "identidades locales" a través de la imagen de marca de producciones específicas, y la relación entre evolución tecnológica, nuevas relaciones sociales y nuevas prácticas culturales .

Por nuestra parte, emprendimos una reconceptualización que creímos totalmente necesaria. Ambos enfoques, el sociológico italiano y el etnológico francés, eran necesarios pero unidimensionales: el uno por centrarse exclusivamente en lo ideático, el otro por poner casi todo el énfasis en lo económico. Y ambos centraban su atención sobre el ámbito de lo laboral. Como intento de superar éstas y otras limitaciones, partimos de la inserción de los procesos de trabajo en los procesos productivos, es decir, subrayamos la necesidad de no pensar los procesos de trabajo en abstracto sino en su desarrollo concreto bajo relaciones sociales de producción específicas. Y planteamos que las características, en todos los órdenes, de un proceso de trabajo vividas desde una posición determinada en las relaciones de producción se hallan en la base no sólo de las condiciones materiales de existencia de los trabajadores sino que condicionan, influyen e impregnan todos los ámbitos de la vida social y de las representaciones ideáticas de estos: desde las opciones o estrategias matrimoniales hasta la forma de representarse el mundo, de vivir la cotidianidad o el tiempo de fiesta, de asumir o no unos u otros valores sociales. En los procesos de trabajo, pues, desarrollados en el marco de unas relaciones de producción determinadas - para el mundo actual capitalistas-, no sólo se producen mercancías y se reproduce el orden ideológico, como se ha señalado siempre desde la perspectiva marxista, sino que se genera también una cultura desde el trabajo, integrada tanto por elementos materiales como ideáticos, que afecta e influye no sólo a lo relacionado con el ámbito laboral, a las prácticas, concepciones y valoraciones en relación a este, sino también a cuanto refiere a los demás ámbitos de la vida social y de las concepciones de los individuos. Así, por poner sólo dos ejentplōs, la 
conciencia del riesgo laboral tan presente en los mineros hace que las pautas de consumo de estos sean muy distintas a las propias de los obreros industriales o de los jomaleros agrícolas. Y la valoración de la disciplina y la obediencia dentro de actividades y profesiones como la militar se proyecta en las relaciones dentro de las familias de militares, haciendo que las normas en el interior de éstas tiendan a estar mucho más formalizadas que, pongamos por caso, en las familias de artistas.

El concepto de culturas del trabajo así esbozado no es un concepto aislado sino que se inserta en un marco teórico-metodológico concreto, el de la matriz estructural, fuera del cual pierde su virtualidad.

Entendemos por ésta al conjunto de los tres tipos de relaciones sociales que entendemos como estructurales, es decir como irreductibles aunque estén fuertemente imbricadas: las relaciones de producción, las relaciones de sexo y las relaciones interétnicas. Por contraste con los análisis marxistas, para los cuales las relaciones sociales de producción, y su resultante la estructura de clases, son las únicas responsables, en última instancia, de todas las desigualdades sociales y el motor de la historia; y en contraste también con los posicionamientos etnicistas y androcéntricos, partimos de la existencia de tres principios estructurales: el productivo, el de sexo-género y el étnico. Y entendemos que en el marco de formaciones sociales y épocas históricas concretas, cada una de estas relaciones sociales estructurales genera un sistema de identidades colectivas que son también estructurales: las identidades productivas (de clase y socioprofesionales), las identidades de sexo-género y las identidades étnicas. $Y$ poseen contenidos culturales, tanto materiales como ideáticos, que no son estáticos sino que están en continua modificación, a los cuales denominamos culturas de la producción, que en sociedades capitalistas se concretan en culturas empresariales y culturas del trabajo ; culturas de género, en nuestro ámbito civilizatorio básicamente masculina y femenina; y culturas étnicas: andaluza, catalana, japonesa, etc. Dichas culturas no son reificables, es decir, no se materializan en la realidad social, aunque son detectables en ella; su existencia es conceptual, y por ello no podemos adjudicarlas, en forma "pura" a los colectivos identitarios que generan, en un marco societario concreto, las relaciones de producción, las relaciones de género y las relaciones interétnicas. Dichas identidades estructurales, por contraste, sí pueden ser asumidas conscientemente, en contextos específicos, por los colectivos resultantes del depliegue de las relaciones sociales estructurales mediante el uso como marcadores de identidad de rasgos y características de las respectivas culturas étnicas, de género o productivas, que son cargados de significación. Rasgos y características que pueden pertenecer tanto al ámbito de lo económico como al de lo político o lo simbólico. 
Los principios estructurales étnico, de sexo-género y productivo son irreductibles, es decir, no pueden ser subsumidos uno en otro ni ninguno de ellos es variable dependiente de alguno de los demás. Pero ello no quiere decir que funcionen de manera independiente; antes al contrario, funcionan imbricados: por eso los contenidos culturales de las relaciones sociales que establecen no existen en forma pura, separada. Creer esto último sería caer en el frecuente error de la reificación. Así, si bien es correcto hablar, por ejemplo, de cultura andaluza, de cultura femenina o de cultura del trabajo jornalera, no podemos pretender ver encarnadas cada una de ellas, separadamente, en un colectivo concreto que esté definido estructuralmente tan sólo por uno de los principios estructurantes de la realidad social, ya que no existen andaluces abstractos sin que tengan a la vez una identidad como hombres o como mujeres y sin estar inmersos en un/unos procesos de trabajo concretos desde la pertenencia a una clase social. Al igual que no existen hombres y mujeres en abstracto, sino teniendo, a la vez, una identidad andaluza, o vasca, o quebecoise, y desarrollando actividades en el hogar, en una fábrica textil o en una aula... Y de la misma manera que tampoco existen en abstracto jornaleros agrícolas, mineros, maestros o agentes de seguros que no tengan también una identidad como hombres o como mujeres, y como andaluces, o catalanes o japoneses...

Debido a esto, en la generación de los contenidos de las culturas del trabajo actúan no sólo los procesos productivos, en las dimensiones material e ideática de los procesos concretos de trabajo vividos bajo relaciones de producción determinadas, sino también los principios de sexo-género y étnico, por lo que todas las culturas del trabajo están internamente generizadas y etnizadas. Ello hace, por ejemplo, que, al menos en nuestro ámbito societario, la cultura del trabajo de los obreros de la construcción o de los mineros estén fuertemente impregnadas de rasgos de cultura masculina, y que la cultura del trabajo doméstica y las culturas del trabajo que se construyen sobre actividades asistenciales estén fuertemente "feminizadas". Y explica también que no compartan una similar cultura del trabajo los obreros de fábricas de autómoviles de Chicago, Dusseldorf o Linares, aunque todas ellas puedan responder a un mismo tipo de organización de la producción, porque los correspondientes trabajadores poseen una diferente etnicidad.

El conocimiento del bagaje, tanto material como ideático, contenido en una concreta cultura del trabajo nos ayudará sobremanera a saber el grado de facilidad o de dificultades para la adaptación de quienes la poseen a otros procesos productivos concretos diferentes a aquel en que se insertaban, $o$ a un cambio en la posición antes ocupada en las relaciones sociales de producción, es decir, en el sistema de clases. Este conocimiento debería ser obligado antes de emprender cualquier planificación que quiera ser realista de cursos de formación ocupacional, planes de empleo, acciones de desarrollo local o puesta en marcha de cooperativas, sociedades anónimas laborales u otras iniciativas de este tipo. En todas 
ellas, los contenidos de la cultura del trabajo de procedencia pueden constituir un bagaje positivo o un lastre para la inserción en nuevos procesos o tareas de producción y en nuevas posiciones estructurales.

\subsection{La penetración de la nueva ideología dominante en las culturas del trabajo.}

Por otra parte, es necesario prevenirnos para no caer en el ingenuo simplismo de pensar que todos los componentes de la cultura del trabajo de un colectivo concreto de trabajadores son resultado de la interpretación de las experiencias de la producción desde la posición de clase a la que sus miembros objetivamente pertenecen. Antes al contrario, en el interior de aquella se hallan presentes representaciones ideáticas, sobre todo de tipo interpretativo, que proceden de la ideología dominante sobre el trabajo y que legitiman las relaciones de producción desigualitarias. Es en las culturas empresariales donde esta ideología tiene su lugar propio pero también incide fuertemente en el ámbito de las culturas del trabajo. Ello no nos autoriza a afirmar, sin embargo, como suele hacerse desde perspectivas marxistas, que sea en los propios procesos de producción donde, junto a la producción de mercancías, se generen las formas de conciencia mixtificada sobre las que se sustenta el consentimiento de dominación. Estimo que no son los procesos productivos el único ni principal núcleo de reproducción de la falsa conciencia sobre el trabajo y su significado, sino los aparatos de Estado: educativos, jurídicos, de comunicación y otros.

Es sobre todo a través de éstos como las nuevas ideas que genera el sacro hoy dominante, el Mercado: competitividad, aumento imprescindible de la productividad, necesidad de prejubilaciones, trabajo flexible y otras semejantes han penetrado y continúan penetrando en las culturas del trabajo de la mayor parte de los trabajadores aunque ello choque con valores sociales que estaban, o parecían estar, firmemente establecidos en ellas, ya que respondían a una interpretación de la experiencia desde su posición de clase o a la antigua ideología dominante sobre el trabajo, aquella que en su versión calvinista, católica o ilustrada contemplaba el trabajo como medio de realización personal, y en su versión marxista subrayaba su centralidad en la toma de conciencia colectiva.

A la ofensiva ideológica neo(ultra)liberal, encaminada a que todos interioricemos como verdades axiomáticas las nuevas ideas sobre el trabajo y la "empleabilidad" que corresponden al nuevo modelo de capitalismo oligopólico neotecnológico, se une la creciente dificultad que las nuevas formas de organización del trabajo que caracterizan a dicho modelo suponen para la posibilidad de reproducción de los aspectos más claramente de clase existentes en las culturas del trabajo que surgieron en los procesos productivos que caracterizaron el desarrollo del capitalismo desde la segunda mitad del siglo XIX hasta los años 70 del XX. De aquí que nos encontremos hoy en una situación de crisis generalizada de los 
valores que en las diversas culturas del trabajo expresan y refuerzan (o expresaban y reforzaban) la interpretación de la experiencia colectiva de los trabajadores desde su propia posición en el proceso productivo: valores que subrayaban la importancia de la unión, la dignidad en el trabajo, la valoración del trabajo bien hecho, el desarrollo de la sociabilidad entre iguales...

Especialmente ejemplificador ha sido el proceso sufrido, en relativamente pocos años, por la cultura del trabajo de los jomaleros andaluces. En este caso, la actuación directa del Estado ha sido determinante para la pérdida, o al menos gran debilitamiento, de varias de sus más importantes características, como eran la aspiración a la tierra, la legitimación de la propiedad sólamente a través del trabajo, la denuncia del destajo en determinadas tareas, o la disposición a efectuar fuertes presiones, de distinto tipo según la época y el contexto, para conseguir mejoras salariales. Como es sabido, la puesta en marcha, a finales del franquismo, del sistema del "Empleo Comunitario" tuvo como efecto sobre los campesinos sin tierra andaluces - que es la conceptualización más adecuada al menos para una buena parte del casi medio millón de obreros agrícolas existentes entonces en Andalucía - su alejamiento de la reivindicación no sólo de la tierra sino también del trabajo, sustituyendola por la reivindicación "del dinero del paro", es decir, de subsidios estatales que, por una parte, eran un medio confesado de comprar paz social, y, de otra, minaban las bases de la cultura jornalera y de la propia identidad del colectivo al alejar a éste de la confrontación con la clase de los propietarios agrícolas, referencia inexcusable respecto a la cual —contra la cual-, habían construido históricamente su propia identidad colectiva. Lo que desembocó rápidamente en su conversión mayoritaria en genéricos desempleados rurales. El apoyo, consciente o no poco importa, de las grandes centrales sindicales a esta hábil maniobra - el SOC fue a estos efectos una excepción, con su política de toma simbólica de tierrăs y sus acciones contra la mecanización indiscriminada-, propició que las movilizaciones durante la transición política fueran desviándose crecientemente del objetivo de la tierra y del trabajo y centrandose en los subsidios, exigidos delante de los Ayuntamientos. Luego, ya en 1984, cuando el PSOE sustituye el "Empleo Comunitario" por el Subsidio de Desempleo Agrícola , la dinámica se acentúa: ya no son ni siquiera los Ayuntamientos los destinatarios de las reivindicaciones sino la instancia más lejana y abstracta del Estado. El cada vez más acentuado y estructural paro agrícola, las pequeñas y aceptadas corruptelas fomentadas por un caciquismo de nuevo tipo, representado por algunos burócratas sindis cales locales y por no pocos alcaldes "de izquierda", y el nuevo poder de los propietarios, a quienes les fue otorgada la potestad de que con su firma cualquier persona fuera introducida en el censo de obreros y obreras agrícolas y pudiera cobrar el subsidio, anularon prácticamente las bases, materiales e ideáticas, sobre las que se sustentaba la reproducción de los valores tradicionales de la cultura del trabajo jornalera y de la propia identidad de los jor- 
naleros como colectivo. Y en especial condenó a la mayor parte de los jóvenes rurales a ser permanentes subsidiados sin aspiración a la tierra ni, en muchos casos, al trabajo.

\section{Consideraciones finales}

La sociedad rural andaluza responde ya, desde hace más de una década, al modelo tripartito que más arriba expusimos. Pero es, sobre todo, en las grandes ciudades andaluzas, en algunas de las cuales el porcentaje de paro sobre la población activa rebasa el $35 \%$, donde las fracturas entre los tres bloques de integrados, precarios y marginados se presentan con mayor crudeza. No todo el porcentaje señalado se adscribe al tercero de estos sectores, ya que una parte de los oficialmente sin empleo realizan indudablemente trabajos negros o se insertan en la economía sumergida o informal —diversas maneras de denominar tecnocráticamente a la sobreexplotación basada en la creciente precariedad laboral- En todo caso, si al 32\% de desempleo que existe hoy oficialmente en Andalucía añadimos cuantos tienen contratos de trabajo legalizados de carácter temporal, a tiempo parcial o de aprendizaje, que suponen la inmensa mayoría de los contratos firmados tras la reforma (o mejor contrarreforma) del mercado de trabajo impuesta por el gobierno de Felipe González como respuesta a la crisis del 93, y a los trabajadores directamente amenazados con un cercano cierre de sus empresas o por reducción de plantillas, y sumamos a todos los anteriores los prejubilados, los pensionistas con bajas pensiones y las mujeres sin subsidio ni empleo y ya fuera del censo de población activa, no creo exagerado señalar que ya hoy casi dos tercios de la población andaluza se encuentra en situación de precariedad o de marginación. Proporción terrible que irá en aumento, de continuarse las dinámicas actuales, ya que se irán añadiendo los antiguos trabajadores de sectores y empresas desmantelados y los inmigrantes magrebíes y subsaharianos que constituyen, ya hoy, una mano de obra imprescindible en muy concretos sectores y actividades, como el de la agricultura intensiva bajo plásticos de la costa almeriense o la recolección de aceituna en Jaen, los cuales estarán, por definición legal y social, siempre a caballo entre la precariedad y la marginación con escasísimas posibilidades de pasar al bloque de los integrados.

Un panorama como éste no es sólo económicamente rechazable - por dejar de utilizar el grueso de los ahora llamados Recursos Humanos existentes en Andalucía-, y moralmente muy injusto, sino que es también socialmente peligroso ya que refleja una desvertebración social poco posible de mantener en un marco democrático. Entiendo que es por poseer el bagaje de sus culturas del trabajo, interiorizadas en su anterior vida laboral, por lo que buena parte de ese altísimo porcentaje de la población hoy marginada $y$, sobre todo, en precario no desemboca en comportamientos abiertamente asociales o se hunde en la degradación moral. Una serie de valores inscritos en las culturas del trabajo andaluzas están actuando a modo de escudo de resistencia. Pero, si continuamos con la dinámica actual, en 
la línea del modelo neo(ultra)liberal y de su ideología sobre el trabajo, ¿qué ocurrirá en las próximas décadas cuando el contenido de las culturas del trabajo se haya transformado, al transformarse las bases materiales y las formas de organización de los procesos productivos y no poderse reproducir, en sectores cada vez más amplios de la población, dichos valores? La cultura del trabajo de la mayoría de los jóvenes actuales difícilmente podrá poseer valores sociales que generen actitudes y prácticas basadas en la autoestima a través del trabajo y la solidaridad entre quienes son conjuntamente explotados sencillamente porque cada vez se dan menos las bases materiales e ideáticas para ello: porque o no tienen empleo o éste no posee la duración y condiciones necesarias para permitir la generación de dichos valores y su interiorización por los sujetos sociales. Y yerran quienes creen que, por ello, los jóvenes desempleados o que realizan trabajos temporales o a tiempo parcial en las actividades más diversas no poseen cultura del trabajo. Lo que ocurre es que ésta consiste, crecientemente, en la ideología dominante sobre el trabajo, que ya sabemos es hoy la ideología neo(ultra)liberal, sin que a ésta se añadan, contradictoriamente, los rasgos generados desde las vivencias de un proceso productivo vivido en común con otros trabajadores.

Desgraciadamente, este continuo retroceso de los aspectos más valiosos, por solidarios y liberadores, de las culturas del trabajo, combinado con el equivalente avance de la actual y fuertemente alienante ideología neo(ultra)liberal sobre el trabajo, que está ya ocupando la centralidad de las culturas del trabajo de muchos sectores de trabajadores, nos dibuja un futuro no precisamente alentador: una sociedad fuertemente desvertebrada, con fracturas internas no coincidentes con las generadas por la estructura de clases tradicional -en la que, por ello, partidos políticos y sindicatos quedan obsoletos al responder a una realidad que ya no existe-, y profundamente deshumanizada porque los hombres y mujeres acentuarán su papel de simples mercancias en el mercado y de instrumento de los intereses económicos en lugar de ser sujetos sociales que aspiren a poner estos al servicio de sus necesidades históricas.

En relación a los otros dos principios estructurales, el étnico y el de sexo-género, aunque no podamos aquí profundizar en ello, conviene ser conscientes de que se están produciendo sendas dinámicas equivalentes y conectadas a la expuesta: la ideología de la "globalización cultural" y la "ciudadanía del mundo", que son presentadas como progresistas por la doctrina neo(ultra)liberal -que ha encontrado, en este punto, un curioso y suicida aliado en el reduccionismo "internacionalista"-, avanza queriendo arrasar las especificidades culturales y la identidad de los grupos étnicos y etnonacionales. Y los valores androcéntricos, que como la competitividad o la agresividad tan bien encajan en la doctrina neo(ultra)liberal, penetran, también a gran velocidad, en el colectivo identitario de las mujeres, haciendo que la reivindicada igualdad entre los sexos se esté realizando, en gran medida, en base al modelo de la cultura de género masculina. 
¿Qué queda, pues, que hacer ante todo lo anterior? Modestamente, considero que es prioritario realizar el análisis de las realidades de nuestro mundo contemporáneo partiendo del marco teórico-metodológico que estamos propugnando para superar las limitaciones tanto del reduccionalismo materialista como del esencialismo ideográfico. Rechazando los simplismos con los que, desde una y otra posición, se ha tratado el tema de la relación entre lo material y lo idéatico y rechazando también, por reduccionista, la consideración de que existe un solo principio estructurante de la realidad social. Y respecto a la práctica social y política, entiendo que no hay otra posición, si no queremos colaborar al avance, supuestamente imparable, de la ideología alienadora del pensamiento único, del fin del trabajo y del fin de la Historia, que convertir los aspectos más liberadores y profundamentes humanos - por nacidos en la experiencia de la relación con la naturaleza y con los otros seres humanos poniendo en juego valores de uso-- de las culturas del trabajo, de las culturas étnicas y de las culturas de género (en este caso, sobre todo de la "cultura femenina"), en ejes de resistencia frente al avance demoledor de la ideología neo(ultra)liberal para la cual sólo existen los valores de cambio y únicamente interesa cuando tiene un precio en el mercado.

\section{BIBLIOGRAFÍA}

BOTTIGLIERI, B. Y CERI, P. (1987): LE CULTURE DEI LAVORO . Il MULINO, BOLONIA.

CULTURES DU TRAVAIL. IDENTITÉS ET SAVOIRS INDUSTRIELS DANS LA FRANCE CONTEMPORAINE (1989). ED. DE LA MAISON DES SCIENCES DE L'HOMME. PARIS.

GODELIER, MAURICE (1989): LO IDEAL Y LO MATERIAL . TAURUS, MADRID.

MORENO, ISIDORO (1990): "CULTURA DEL TRABAJO E IDEOLOGIA: EL MOVIMIENTO ANARQUISTA CAMPESINO ANDALUZ", EN ACTAS DEL IV CONGRESO DEL ANDALUCISMO HISTORICO, CÁDIZ, 1989 , PP. 77-93. Fundación Blas INFANTE, SEVILla.

- (1991): “IDENTIDADES y RituAles. Estudio INTROductorio", en J. PRAT, U. MARTínez, J. Contreras e I. Moreno (eds.): Antropología de los Pueblos de España , PP. 601636. MADRID.

- (1993A): ANDALUCÍA: IdENTIDAd y CULTURa (Estudios de ANTRopología ANDALUZa). Ed. LIBRERÍA AGORA. MÁlAGA.

- (1993B): “¿PROCESO DE SECULARIZACIÓN O PLURALIDAD DE SACRALIDADES EN EL MUNDO CONTEMPORÁNEO?”, EN EL MITO Y LO SAGRAdO EN EL PENSAMIENTO CONTEMPORÁNEO. SEVILLA.

- (E. P.): "MATRIZ ESTRUCTURAL, SISTEMAS DE IDENTIDADES E IDENTIFICACIONES COLECTIVAS".

TRTI, ALFONSO (1984): “CRISIS DEL MODELO NEOCAPÍTALISTA Y REPRODUCCIÓN DEL PROLETARIADO RURAL. (REPRESIÓN, RESURRECCIÓN Y AGONÍA FINAL DE LA CONCIENCIA JORNA- 


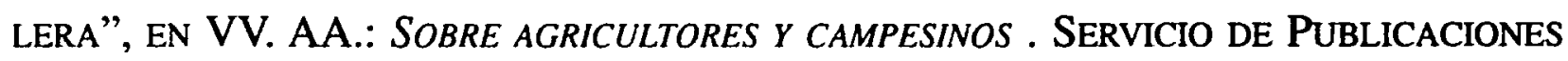
DEL MAPA, MADRID. -

- (1994): "DE la dUALIZACIÓN A LA DEMOCRATIZACIÓN DEL TRABAJO". ÉXODO, № 22, PP. 40-46.

PalenZUEla, Pablo (1991): "El Estado No inocente. Naturaleza perversa y EFICIENCIA DE LA POLÍTICA ASISTENCIAL EN EL MUNDO RURAL ANDALUZ". REVISTA DE ESTUDIOS REGIONALES , № 31, PP. 213-222.

- (1995): "LAS CULTURAS DEL TRABAJO: UNA PERSPECTIVA ANTROPOLÓGICA". SOCIOLOGÍA DEL TRABAJO, № 24, PP. 3-28.

- (1996): "El trabajo, objeto de estudio para la ANTropología", en P. Palenzuela (COORD.): ANTRopología del TRABajo. VI CONGRESO de ANTROPOlogía SOCIAL, PP. 1118. ZARAGOZA.

ROCA I GIRONA, JORDI (1996): "IDEOLOGÍA SOBRE EL TRABAJO Y SATISFACCIÓN LABORAL", EN P. PALENZUEla (COORD.): ANTROPOlOGia DEL TRABAJO , PP. 19-26. ZARAGOZA.

RUFKIN, JEREMY (1996): EL FIN DEL TRABAJO . TAURUS, MADRID.

TALEGO, FÉlIX (1995): “CULTURA DEL TRABAJO JORNALERA, DISCURSO POLÍTICO Y LIDERAZGO: EL CASO DEL PODER POPULAR DE MARINALEDA". ANTROPOLOGIA , № 4, PP. 131-151.

- (1996): ENTRE EL TRABAJO Y LOS SUBSIDIOS DEL ESTADO: LOS JORNALEROS DE LEBRIJA . LEBRIJA.

ZURLA, P.: "CAlidad y Cultura del trabajo en los años ochenta". Sociología Del TRABAJO , № 8, PP. 109-133. 